\title{
An Empirical Study on Efficient Market Hypothesis of Indian Capital Market (NSE Sectorial Indices)
}

\author{
Ms Pooja Yadav1, C. A. Dr. D. S. Patil ${ }^{2}$ \\ ${ }^{1}$ Student, ${ }^{2}$ Associate Professor \\ ${ }^{1,2}$ Chhatrapati Shahu Institute of Business Education and Research. \\ Shivaji University, Kolhapur, Maharashtra, India
}

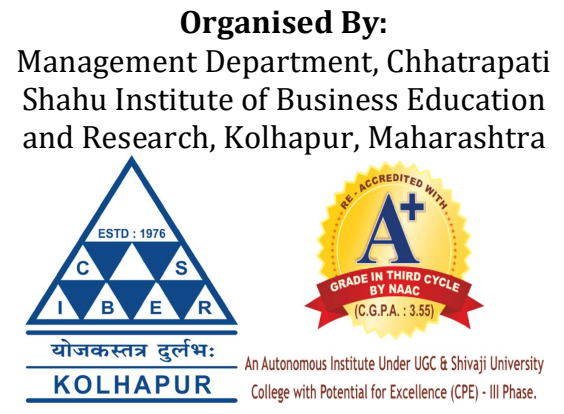

How to cite this paper Ms Pooja Yadav| C. A. Dr. D. S. Patil "An Empirical Study on Efficient Market Hypothesis of Indian Capital Market (NSE Sectorial Indices)" Published in International Journal of Trend in Scientific Research and Development (ijtsrd), ISSN: 2456-6470, Special Issue | Fostering Innovation, Integration and Inclusion Through Interdisciplinary

Practices

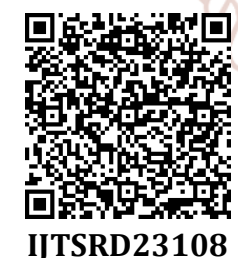

Management, March 2019, pp.222-225, URL:

https://www.ijtsrd.c om/papers/ijtsrd23 108.pdf
ABSTRACT

As long as financial markets are concerned, for many year's economists, statisticians and financial analyst have been interested in developing and testing models of stock price behaviour and their forecast. This study examines whether the Indian stock market is efficient, if the stock returns follow a random walk. The study employs daily closing prices of NSE Sectorial Indices for a time period of 1 April, 2008 to 31 March, 2018. The existence of random walk for NSE Sectorial Indices has been examined through auto correlation, run test and finds that the Indian stock market was not efficient in the weak form during the testing period. The results suggest that the stock prices in Indian do not reflect all the information in the past stock prices and abnormal returns can be achieved by investors through exploiting the market inefficiency.

KEYWORDS: Auto correlation tests, run test, Random walk Hypothesis (RWH), 7 NSE Sectorial Indices viz. Pharma, Bank, IT, Financial Services, FMCG, Auto, MNC

\section{INTRODUCTION}

Efficient Market Hypothesis (EMH) is an important theory in finance for understanding of the equity markets and cost of equity capital. In terms of capital market theory, the concept of market efficiency is used to explain the degree to which stock prices reflect the available and relevant information at any given point in time.

The efficient market hypothesis propose that the stocks always trade at their fair value on stock exchange, which makes it impossible for investors to either purchase undervalued or sell overvalued stocks. It suggests that the current stock price fully reflects all the available information regarding a firm and hence it is impossible to beat the market using the same information.
In other words, you cannot beat the market by using the information that is already available to public as the market has already incorporated and reflected all the relevant information which may impact the stock.

According to the efficient market hypothesis, the market price of a stock adjusts quickly and on average without any bias to the new information. As a result, prices of the securities reflect all the available information in a timely manner. That's why EMH suggests that there is no reason to believe that prices are too high or too low. The security prices adjust before an investor has time to trade or make profits from an exactly what he paid for.

The efficient market hypothesis is related to the random walk theory. There are three levels of efficiency i.e. weak, semi-strong and strong form. These forms of efficient market depend upon the information set and relation to prices. If the information based on historical prices, the market is its weak form. The weak form of EMH suggests that the current prices of a stock fully incorporate information contained in the price history of stock. It's directly challenges the technical analysts whose trades are based on the past price movements and chart trends.

The semi-strong form of efficient markets includes the information set of all public information. All the information likes past price movements, financial statements, corporate announcements, and economic factors already reflects in the share price. This form of EMH suggests that it is useless to read financial statement, industry or economy and make your investments decision on it. It's directly challenges the fundamental analysts who believe in making a profit from the market by studying the fundamentals of a stock. 
Lastly, if the information is insider information the market is said to be in its strong form. The strong form proposes that nobody should be able to generate profit systematically based on insider information, which is not even publicly known at the time.

This study is based on weak form of EMH, which analyzes the daily closing rates of various sectorial indices of NSE India from $1^{\text {st }}$ April, 2008 to $31^{\text {st }}$ March 2018 by using some commonly used methodologies to determine whether the Indian market is efficient in the weak form.

The objective of the study is:

$>$ To find out whether the past prices of the stock are reflected on the future price

$>$ To find out whether the weak form of efficient market of the different sectorial indices of NSE holds true or not

\section{LITERATURE REVIEW}

Various researches have been carried out in different period to test the efficiency of Indian capital market in the weak form, but the results have been inconclusive. Some studies find the market is efficient in the weak form but others find the market is inefficient in the weak form. Some of which are summarized below:

Shukla, D. D. (2017) analyzed the efficiency of the Indian stock markets by using the daily closing prices of BSE Small Cap index for the time period of 04 jan, 2012 to 12 Dec, 2016. The existence of random walk for BSE Small Cap index has been examined through auto correlation, Q-statistics and the run test and finds that the indian stock market was not efficient in the weak form during the testing period. The result suggest that the stock prices in india do not reflect all the information in the past stock prices and abnormal returns can be achieved by investors through exploiting the market inefficiency.

Anjala Kalsie, J. K. (April 2015) have analysed the market of 6 major NSE sectorial indices i.e. Pharma, IT, MNC, Bank, FMCG and Nifty Junior. Univariate time series analysis of indices return is carried using tests for randomness/non-stationary - run test, unit root testing, auto correlation function, correlograms and other relevant statistical methods. The study concludes that Indian market are inefficient in its weak form for the study period.

Neeraj Gupta, A. G. (Aug. 2014) tested for the weak form of efficient market hypothesis using closing stock prices of various top automoblie and IT companies of India taken from NSE. Runs test has been used to find out market efficiency. The study showed that Indian stock market was weak form efficient.

Ramkumar, R. E. (2012) have analysed the market efficiency of sectorial indices of BSE India and found that the return of 8 indices out of 12 indices, namely, BSE Automobile Index, BSE Bankex, BSE Capital Goods Index, BSe Realty Index followed normal distribution and earned better return at 5 peercent significance level.

Patrick, A. a. (2011) have compared the weak form of efficiency of NSE and NYSE and has presented the evidence of efficient from of NSE and inefficient form of NYSE. Form autocorrelation analysis and run test it eas conlcuded that the series of stock indices of NSE is unbaised random time series whereas stock indices of NYSE is baised random time series.

Hiremath, G. a. (2010) find that the Indian stock markets are weak form efficient but not all the time. Their tests showed that CNX Nifty Junior, CNX 500, CNX Bank Nifty, BSE 500, BSE Midcap and BSE Small cap reject the random walk hypothesis and return series are characterized by the presence of linear dependencies.

Poshakwale, S. (1996) showed that Indian stock market was weak form efficient; he used daily BSE index data for the period 1987 to 1994.

Belgaumi, M. S. (1995) conducted an intensive study on the efficiency of BSE. He studied the weekly share prices of 70 companies listed in the 'A' list category on BSE. He used serial correlation and run test and found that the Indian stock exchanges are efficient in the weak form and that the independence assumption regarding the movements of share prices over short period holds good.

Thus, in the Indian contex, apart from a few studies, the available information in general points out to the fact that the consecutive price changes are independent and the trends in movement of stock prices in Indian market can be explained by random walk model.

\section{RESEARCH METHODOLOGY}

\section{Research Design}

The study aimed to know the random walk of NSE Sectorial indices; hence the research design of the study is descriptive in nature.

\section{Data}

The study considers the period of last 10 year from 1 April 2008 to 31 March 2018. The data collected for the study are discussed below.

Sectorial Indices: The study has been carried out based on NSE sectorial indices i.e. Nifty Pharma, Nifty Bank, Nifty IT, Nifty Financial services, Nifty FMCG, Nifty Auto, Nifty MNC; that were part of the index from 1 April 2008 to 31 March 2018.

Sources of data: The required data on indices was collected from Centre for Monitoring Indian Economy (CMIE) database, PROWESS, the National Stock Exchange (NSE) website.

Study Type: The study type is Analytical and historical data is been used for the analysis. Analytical because facts and existing information is used for the analysis as relationship is examined by expressing variable in measurable terms and also historical information is used for analysis and interpretation.

Sampling Frame: Sampling frame includes the daily closing prices of seven sectorial indices on National Stock Exchange. Sample includes historical closing prices for the period of last 10 years from 1 April 2008 to 31 March 2018.i.e. 2475 days. 
International Journal of Trend in Scientific Research and Development (IJTSRD) @ www.ijtsrd.com eISSN: 2456-6470

\section{Research Plan:}

Hypothesis testing: While studying the efficient market hypothesis, hypothesis testing has been taken into account. The hypothesis which is tested under the assumption that it is true is called null hypothesis and is denoted by HO. The hypothesis which differs from a given null hypothesis, H0 and is accepted when $\mathrm{HO}$ is rejected is called an alternative hypothesis and is denoted by H1. Thus, in context of this research we have,

H0: Past prices are not reflected on the present prices (independent)

H1: Past prices are reflected on the present prices (dependent)

\section{The methodology adopted for the study}

For the present study time series analysis technique such as autocorrelation or/and run tests is to be used. But in present study only run tests is used. Here, utility of the case are discussed.

\section{Autocorrelation:}

The term autocorrelation is defined as correlation between members of series of observation ordered in time or space. It is a parametric test. It is the lag correlation of a given series with itself lagged by a number of time units. Autocorrelation is a reliable measure for testing of independence of random variables in return series. Autocorrelation tests show whether the serial correlation coefficients are significantly different from zero. In an efficient market, the null hypothesis of zero autocorrelation will prevail. This test statistic is widely used to notice any perceptible trend in stock prices. In the present study we have considered time lags of 1-10 days. Autocorrelation in the data was checked using Autocorrelation function (ACF) and correlograms utilizing the Ljung Box statistic, Dubin-Watson statistic. (Anjala Kalsie, April

2015)

The autocorrelation function (ACF) test is examined to identify the degree of autocorrelation in a time series. It measures the correlation between the current and lagged observations of the time series of stock returns. A series of data may have observations that are not independent of one another. Autocorrelation Coefficients measure correlations between observations a certain distance apart. Based on the ordinary correlation coefficient ' $r$ '. An autocorrelation coefficient at lag $\mathrm{k}$ can be found by:

$$
r k=\frac{\sum_{t-1}^{N-k}(\mathrm{Xt}-\mathrm{x})(\mathrm{Xt}+\mathrm{k}-\mathrm{x})}{\sum_{t-1}^{N-k}(X t-x)^{2}}
$$

Where, $\mathrm{rk}=$ correlation coefficient

$\mathrm{X}=$ random variable

$\mathrm{t}=$ time

$\mathrm{x}=\mathrm{X}$ bar

$\mathrm{k}=1,2,3, \ldots . . \mathrm{n}$ (days)

A plot of rk against $\mathrm{k}$ is known as correlogram. If time series has unit root, than the autocorrelation function slowly decrease starting from the value of one and the partial auto correlation function has only first value which differs from zero. If one time series has two unit roots, ACF act the same way as for the one unit root series, but the PACF has only first two nonzero values. The serial correlation matrices that measures correlation between price changes inconsecutive time periods and is a measure of how much price change in any period depends upon price change over the previous time period. A serial correlation of zero would imply that price changes in consecutive time periods are uncorrelated with each other, and can thus be viewed as a rejection of the hypothesis that investors can learn about future price changes from the past ones. A positive and statistically significant serial correlation could be viewed as evidence of price momentum in markets, and would suggest that returns in a period are more likely to be positive (negative) if the prior period returns were positive (negative). In a more precise way, serial correlation coefficients provide a measure of relationship between value of random variable $(\mathrm{X})$, in time $\mathrm{t}$ and its value $\mathrm{k}$-periods earlier. It indicates whether daily price changes in the period t are influenced by price changes occurring $\mathrm{k}$-days earlier, where $\mathrm{k}=1,2,3 \ldots \mathrm{n}$.

\section{Run Tests:}

The study seeks to test the efficient market hypothesis, by employing Runs Test. Runs Test is a nonparametric test, which is used to test the randomness of the series which auto correlation fails to do. Runs Test is a traditional method used in the random walk model and ignores the properties of distribution. It has been used to judge the randomness in the behaviour of Indian Stock market. In runs test we consider a series of price changes over a certain period of time and each price change is either designated as a plus $(+)$ if it is an increase in price or a minus(-)if it is a decrease in price. A run exist when two consecutive changes are the same (i.e., ++ or--). When price changes in a different direction, such as +-or-+ The run ends and a new run may begin .To test for independence, the number of runs for a given series of price changes are compared with the number of runs for a given series of price changes compared with the number in a table of expected values for the number of runs that should occur in a random series. (Neeraj Gupta, Aug. 2014)

To test the independence of the prices, we require:

Total Number of Runs: (r)

Number of Positive Price Changes: (n1)

Number of Negative Price Changes: (n2)

Once we have the data, the mean and the standard deviation of the mean are calculated by using the formula given below:

Mean, $\mu(\mathrm{r}): \underline{2 \mathrm{n} 1 \mathrm{n} 2+1}$

Standard deviation, $\sigma(r)=2 n 1 n 2(2 n 1 n 2-n 1-n 2)(2)$ $(\mathrm{n} 1+\mathrm{n} 2)^{\wedge} 2(\mathrm{n} 1+\mathrm{n} 2-1)$

Level of significance: To test the weak form of efficiency of the stock market, the Runs Test is applied at $5 \%$ significance level where $\mathrm{z}=1.96$

Calculating lower limit and upper limit: Here, Lower limit : $\left\{\mu-1.96^{*}(\sigma)\right\}(3)$ Upper limit : $\left\{\mu+1.96^{*}(\sigma)\right\}$

(4) Where $\mu=$ mean $\sigma=$ standard deviation

Simply, for this project report only Run test is used for testing the randomness. For the study various sectorial indices used such as Nifty Pharma, Nifty Bank, Nifty It, Nifty Financial services, Nifty FMCG, Nifty Auto, Nifty MNC. 
International Journal of Trend in Scientific Research and Development (IJTSRD) @ www.ijtsrd.com eISSN: 2456-6470

\section{RESULT ANALYSIS:}

Table 1 shows the result of the Run test. This study finds that if the number of runs falls within the upper and the lower limit then it is concluded that the prices are dependent at $5 \%$ level of significance i.e. $\mathrm{H} 1$ rejected. Thus the market is The following table reflect the overall result of the study. weekly efficient and if the number of runs dose not falls then the prices are independent at $5 \%$ level of significance i.e. H0 rejected. Almost in all the cases the number of runs dose not falls within the upper and lower limit except NIFTY FMCG.

Table 1 showing the Result of Hypothesis testing:

\begin{tabular}{|c|c|c|c|c|c|c|c|c|}
\hline Sectorial indices & $\mathrm{n} 1$ & $\mathrm{n} 2$ & $\boldsymbol{\mu}$ & $\boldsymbol{\sigma}$ & $\begin{array}{c}\text { Upper } \\
\text { Limit }\end{array}$ & $\begin{array}{c}\text { Lower } \\
\text { Limit }\end{array}$ & $\begin{array}{c}\text { Observed } \\
\text { Runs }\end{array}$ & $\begin{array}{c}\text { Hypothesis testing at a } \\
\text { given level of significance }\end{array}$ \\
\hline Nifty Pharma & 1312 & 1162 & 1233 & 25 & 1282 & 1185 & 1143 & H0 rejected \\
\hline Nifty Bank & 1300 & 1174 & 1235 & 25 & 1283 & 1186 & 1167 & H0 rejected \\
\hline Nifty IT & 1279 & 1194 & 1236 & 25 & 1285 & 1187 & 1185 & H0 rejected \\
\hline Nifty Fin Services & 1281 & 1193 & 1236 & 24 & 1285 & 1188 & 1181 & H0 rejected \\
\hline Nifty FMCG & 1327 & 1147 & 1231 & 25 & 1280 & 1183 & 1250 & H1 rejected \\
\hline Nifty Auto & 1335 & 1138 & 1230 & 25 & 1278 & 1181 & 1121 & H0 rejected \\
\hline Nifty MNC & 1328 & 1146 & 1231 & 25 & 1280 & 1182 & 1176 & H0 rejected \\
\hline
\end{tabular}

\section{COCLUSION:}

Many studies have been done to test the efficiency of Indian market in the weak form but the results have been in conclusive. Some studies find the market is efficient in the weak form but others find the market is inefficient in the weak form. In this study, we use runs test to analyse daily closing rates of NSE sectorial indices from 01 April 2008 to 31 March 2018. The results of the runs test indicate that the Indian stock market is not random and hence, inefficient in the weak form during our testing period and imply that it is possible to achieve abnormal returns by predicting the future price movements based on past stock price movements.

\section{References:}

\section{Book reference}

[1] Bayross, I. (2015). Information system audit and control Delhi: Pearson Publication.

[2] Brown, R. a. (2012). Investment Analysis And Portfolio Management (10th edition ed.). South-Western.

\section{Research article}

[1] Anjala Kalsie, J. K. (April 2015). An Emperical Study On Efficient Market Hypothesis Of Indian Capital Market. Journal of Management Research and Analysis.

[2] Belgaumi, M. S. (1995). Efficiency of the Indian Stock Market: An Empirical Study .

[3] Fama, E. (1970). Efficent Capital Markets: a Review of Theory and Empirical Work. Journal of Finance, 25, 383-420.

[4] Fama, E. (1970). Efficient capital markets: A review of theory and emperical work. The journal of Finance, 25(2).

[5] Fama, E. (1991). Efficient capital markets. The journal of Finance, XLVI, No.5.

[6] Fama, E. a. (1988). Permanaent and Temporary Component of Stock Prices. journal of Political Economy, 251-276.

[7] Fama, E. F. $(1965 ; 1995)$. The Behaviour of Stock Market Prices. Journal of Business, 38, No 1, 34-105.

[8] Hiremath, G. a. (2010). Some further evidence on the Behaviour of stock returns in India. International Journal of Economics and Finance, 2.
[9] Krishnamurti, K. (2017, June 20). Cryptography and Data Security. Journal Of Security, Vol- III, 48- 50.

[10] Neeraj Gupta, A. G. (Aug. 2014). Testing of Efficient Market Hypothesis: a study on Indian Stock Market. IOSR Journal of Business and Management, 16(8).

[11] P. K. Sinha. (2017, July 05). ERP Implementation. Information system for managment, vol-IV, 32-38.

[12] Patrick, A. a. (2011). Efficiency of stock market Comparing the behaviour of stock Indices of NSE and NYSE. International Journal of Multidisciplinary research, 1(8).

[13] Poshakwale, S. (1996). Evidence on weak form of efficiency and the day of the weak effect in the Indian stock market. Finance India, $X(3)$.

[14] Ramkumar, R. E. (2012). An Analysis of Market Efficiency in Sectoral Indices: A study with a Special Reference to Bombay Stock Exchange in India. European Journal of Scientific Research, 69.

[15] RBI. (2012, December 20). RBI guidanes for I.S Aduit. RBI.

[16] Satish Kulkarni, Pravin Jamsandekar. (2018). Recent trends in research methodology. Jornal of reserach, volume-III(7), 20-30.

[17] Shukla, D. D. (2017). An Empirical Srudy of Random Walk Hypothesis of Indian Stock Market- BSE Small Cap. EduSys International Journal of Management Research, 14.

\section{Online references:}

[1] https://www.nseindia.com

[2] www.businesstoday.in

[3] www.investopedia.com

Copyright (C) 2019 by author(s) and International Journal of Trend in Scientific Research and Development Journal. This is an Open Access article distributed under the terms of the Creative Commons Attribution License (CC BY 4.0) (http://creativecommons.org/licenses

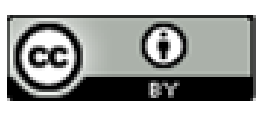
/by/4.0) 